Original Article

\title{
STRESS AND ITS RELATIONSHIP WITH SELECTED FACTORS AMONG WOMEN
}

\author{
Maria Pais', Judith A Noronhna ${ }^{2} \&$ Pavan Bhat $K^{3}$ \\ ${ }^{1}$ Assistant Professor, ${ }^{2}$ Associate Dean, M anipal College of Nursing, M anipal, ${ }^{3}$ Lecturer, Department of Statistics M GM , \\ PU College Udupi, Karnataka India. \\ Correspondence : \\ Maria Pais \\ Department of Obstetrics and Gynecology Nursing, M anipal College of Nursing M anipal, \\ M anipal University, Manipal, Karnataka, India. \\ E-mail : mariapuso@gmail.com \& maria.v@manipal.edu
}

\begin{abstract}
:
Introduction: Stress is a complex, dynamic process of interaction between a person and his or her life. It is the war one reacts physically, mentally and emotionally to the various conditions. The purpose of the present study was to investigate stress, its relationships with selected factors among women.
\end{abstract}

Study Design: A descriptive survey design was used to identify the stress and its relationship with selected factors among (200) women aged 18-45 years.

Results: The present study reveals that level of stress was high among unmarried women (85\%) when compared to married women (76\%). The present study also revealed that there was a significant association between stress and age, age at menarche, education, BM I and dysmenorrhea among the married and unmarried women.

Conclusions: Stress was more prevalent among unmarried women, age, educational status, age at menarche; BM I and dysmenorrhea were strongly associated with stress.

Keywords: Stress, M arried and unmarried women, conceptual frame work.

\section{Background:}

Stress is an inevitable part of life. Human beings experience stress early, even before they are born. Stress is internal or external influences that disrupt an individual's normal state of well-being. These influences are capable of affecting health by causing emotional distress and leading to a variety of physiological changes. The body responds to stress by releasing stress hormones such as epinephrine (adrenaline) and cortisol (hydrocortisone). These hormones help women react to a situation in a strong way. Stress hormones will increase blood pressure, heart rate and sugar levels. Mild stress is beneficial, but long term

\begin{tabular}{|c|}
\hline Access this article online \\
\hline Quick Response Code \\
\hline
\end{tabular}

stress is thought to be harmful. These changes include increase heart rate, increasing hormonal level; this will lead to increase BMI, heart disease, depression and dysmenorrhea. One of the main reasons why women do not consistently and normally ovulate relates to a combination of environmental, nutritional, or emotional stress -induced eating and weight gain. Some studies revealed that high body mass index was found in person who eat and drink in response to stress, particularly in women, it is difficult to separate stress from other physical or emotional factors when examining cancer related risk factors. ${ }^{1,2}$ Biological factors, such as growing older, becoming overweight, are common risk factors for coronary artery disease, diabetes, hypertension, somatic complaints like menorrhagia, pelvic pain and cancer related disease.

The present study is to determine the stress and its relationships with factors such as age, age at menarche, occupation, physical activity, menstrual flow, BMI and dysmenorrhea among women aged 18-45 years in Udupi District, India.

\section{Conceptual framework:}

The conceptual framework for the study was developed 
based on "Fish bone model" (fig.1) (cause and effect diagram 1972), the present study is to determine the stress and its relationship with selected factors among women. The present study aims to identify the risk factors of stress and associated factors associated with stress, the multiple risk factors that predispose to level of stress are grouped as unmodifiable and controlled factors. Unmodifiable factors like age, age at menarche and modifiable factors like life style occupation, poor dietary pattern poor socio economic factors and BM I (fig.1)

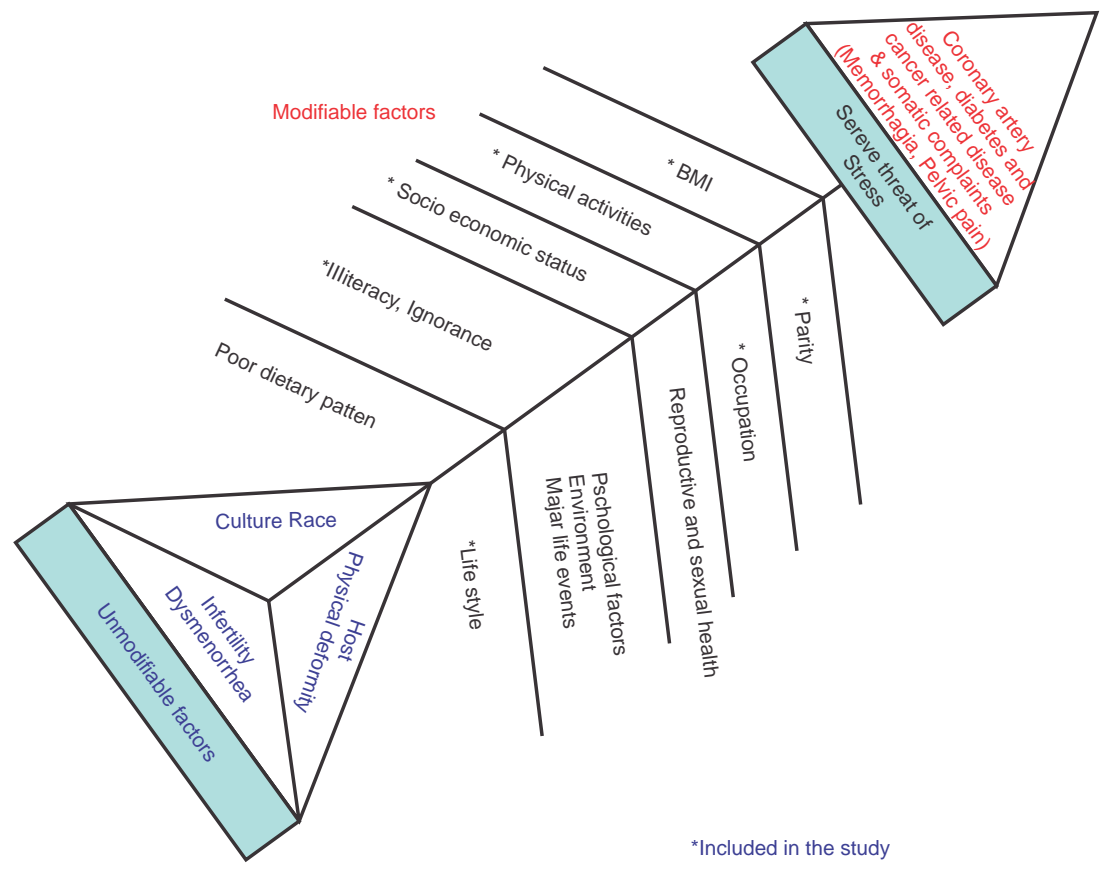

Fig 1: Conceptual Frame work adopted from Fish bone model to identity the factors related to stress

\section{Material and Methods:}

A community based descriptive survey study was carried out in a sub center area of Thenkanidiyoor and Athrady in PHC in Udupi District, Karnataka. the sub center Thenkanidiyoor is a rural area which covers 5,332 population with 2,524 males and 2,808 females and total 423 houses, the total population of Athrady rural area is 2,406 with 1,154 males and 1,252 females population and total 300 houses the women (200) were selected aged 1845 years, who were co-operative and present during the door to door survey, were included in the study. A pretested questionnaire was used to collect information on socio-demographic profile, stress and BMI. SPSS (Version 16.0) package was used to analyses the data. Data was summarized using percentage. Chi-square test was used to test for stress and its asso ciated factors.

\section{Results:}

\section{Severity of stress}

Table 1 shows that out of 100 unmarried women $62 \%$ had mild stress, $17 \%$ had moderate stress and $6 \%$ had severe stress, and $15 \%$ had no stress. With regard to 100 unmarried women having $63 \%$ had mild stress, $8 \%$ had moderate stress and $5 \%$ had severe stress, and $24 \%$ had no stress.

Table 1: Severity of stress among women:

\begin{tabular}{|l|c|c|c|c|}
\hline Stress & \multicolumn{2}{|c|}{ Unmarried (100) } & \multicolumn{2}{c|}{ Married (100) } \\
\hline & $f$ & $(\%)$ & $f$ & $(\%)$ \\
\hline No stress & 15 & 15 & 24 & 24 \\
\hline Mild (1-20) & 62 & 62 & 63 & 63 \\
\hline Moderate (21-40) & 17 & 17 & 8 & 8 \\
\hline Severe (41-60) & 6 & 6 & 5 & 5 \\
\hline
\end{tabular}

\section{Association between stress and selected variables:}

Table 2 shows there was significant association between the level of stress and selected variables like, age $\left(?^{2}=74.667, p<0.001\right)$, age at menarche $\left(?^{2}=5.291, p \varangle 0.021\right)$, education $(?=41.036, p \varangle 0.001)$, BM I $(?=18.990, p \varangle 0.001)$, dysmenorrhea $(?=22.155, p<0.001)$ among the married and 
Table 2: Association between severity of Stress and selected variables:

$(n=200)$

\begin{tabular}{|c|c|c|c|c|c|c|c|}
\hline \multirow[t]{2}{*}{ Variables } & \multicolumn{2}{|c|}{ Unmarried } & \multicolumn{2}{|c|}{ Married } & \multirow[t]{2}{*}{ Chi square } & \multirow[t]{2}{*}{ df } & \multirow[t]{2}{*}{$P^{\prime}$ value } \\
\hline & $f$ & $\%$ & $f$ & $\%$ & & & \\
\hline \multicolumn{8}{|l|}{ Age in years } \\
\hline$\leqslant 30$ & 98 & 98 & 42 & 42 & 74.667 & 1 & 0.0001 \\
\hline$>30$ & 2 & 2 & 58 & 58 & & & \\
\hline \multicolumn{8}{|l|}{ Education } \\
\hline$<10$ Standard & 18 & 18 & 58 & 58 & 41.036 & 4 & 0.0001 \\
\hline$\geqslant 10$ Standard & 82 & 82 & 42 & 42 & & & \\
\hline \multicolumn{8}{|l|}{ Occupation } \\
\hline Unemployed & 42 & 42 & 45 & 45 & & & \\
\hline Unskilled & 41 & 41 & 43 & 43 & 1.511 & 3 & 0.725 \\
\hline Non professional & 3 & 3 & 1 & 1 & & & \\
\hline Professional & 14 & 14 & 11 & 11 & & & \\
\hline \multicolumn{8}{|l|}{ Menstrual flow } \\
\hline Scanty & 1 & 1 & 2 & 2 & & & \\
\hline Moderate & 89 & 89 & 92 & 92 & 1.383 & 2 & 0.574 \\
\hline Heavy & 10 & 10 & 6 & 6 & & & \\
\hline \multicolumn{8}{|l|}{ Age at Menarche } \\
\hline$\leqslant 13$ & 33 & 33 & 49 & 49 & 5.291 & 1 & 0.021 \\
\hline 14-16 & 67 & 67 & 51 & 51 & & & \\
\hline \multicolumn{8}{|l|}{ BMI } \\
\hline$<18$ & 56 & 56 & 29 & 29 & & & \\
\hline $18-22$ & 36 & 36 & 45 & 45 & 18.990 & 2 & 0.0001 \\
\hline$>23$ & 8 & 8 & 26 & 26 & & & \\
\hline \multicolumn{8}{|l|}{ Physical Activity } \\
\hline Mild (1-12) & 11 & 11 & 6 & 6 & & & \\
\hline Moderate (13-24) & 70 & 70 & 67 & 67 & 2.928 & 2 & 0.231 \\
\hline Severe (25-38) & 19 & 19 & 27 & 27 & & & \\
\hline \multicolumn{8}{|c|}{ Socio Economic Status } \\
\hline Low & 66 & 66 & 66 & 66 & 1.015 & 2 & 1 \\
\hline Middle & 34 & 34 & 33 & 33 & & & \\
\hline \multicolumn{8}{|l|}{ Dysmenorrhea } \\
\hline Mild (1-8) & 36 & 36 & 69 & 69 & & & \\
\hline Moderate (9-16) & 55 & 55 & 28 & 28 & 22.155 & 2 & 0.0001 \\
\hline Severe (17-25) & 9 & 9 & 3 & 3 & & & \\
\hline
\end{tabular}

unmarried women, age, age at menarche, education, BMI and dysmenorrhea were the contributing factor for the stress in these selected subjects.

\section{Discussion :}

The present study reveals that level of stress was high among unmarried women (85\%) when compared to married women (76\%). The present study also revealed that there was a significant association between stress and age, age at menarche, education, BMI and dysmenorrhea among the married and unmarried women, higher proportions of unmarried women with increased severity of stress had dysmenorrhea as compared to women with lower level of stress. This study is similar to the study conducted among 1160 Chinese women and found that risk of dysmenorrhea was greatest among women with both high stress and a history of dysmenorrhea compared to women with low stress and no history of dysmenorrhoea ${ }^{3}$. Another study was similar to the study to examine the relationship between perceived psychosocial stress and percent change in BMI among adult black men and women. The observed prospective relation between psychosocial stress and BMI change differed by gender. For 
women, higher levels of stress were associated with greater percentage increases in BMI over the 13 years of follow-up, the relation between psychosocial factors, such as stress, and obesity may be mediated in a number of ways. Psychosocial stress is known to be associated with physiological effects, such as excess levels of the stress hormone cortisol that is known to potentiate visceral fat deposition. ${ }^{4} \mathrm{~A}$ similar study was conducted in United States among 170 Air force Military women and study showed that life event stress was significantly associated with dysmenorrhoea ${ }^{5}$.A recent study released by the Nielsen Company that examines the consumer and media habits of women in emerging and developed countries has found that women in India are the most stressed. Nielsen's survey found that, women play multiple roles that contribute to

\section{References:}

1. Garssen B. Psychological factors and cancer development: Evidence after 30 years of research. Clinical Psychology Review 2004: 24(3):315-338.

2. Dalton SO, Boesen EH, Ross L, Schapiro IR, Johansen C. M ind and cancer: Do psychological factors cause cancer? European Journal of Cancer 2002; 38(10):1313-1323.

3. M cEwen BS, Seeman T. Protective and damaging effects of mediators of stress. Elaborating and testing the concepts of allostasis and allostatic load. Ann N Y AcadSci 1999;896:30-47

4. Angela G. et al. Psychosocial Stress and 13-year BMI change among Blacks: The Pitt County Study. Obesity (2009) 17 11, 2106-2109.

5. Gordley, L.B., Grace L., Susan SR \& James Y.H (2000). Menstrual disorders and occupational, stress, and Racial factors Among Military Personnel, 42(9), 871-881. their stress levels, but that the social infrastructure allowing them to navigate these roles differed between emerging and developed countries. As a result, women in developing countries tended to be more stressed than women in the developed world, with women in India, feeling the most time-pressured.

\section{Conclusion:}

Stress was more among unmarried women when compared to married women age, education, BMI and dysmenorrhea was strongly associated with stress. In summary, stress constitute an important unmet area certain stress reducing complimentary therapy like yoga, meditation, laughing therapy should be given to all women in developing countries and more attention should be given for adopting complimentary therapy for all women. 